\title{
Exploring electronic effects on the partitioning of actinides(III) from lanthanides(III) using functionalised bis- triazinyl phenanthroline ligands
}

Article

Accepted Version

Edwards, A. C., Wagner, C., Geist, A., Burton, N. A., Sharrad, C. A., Adams, R. W., Pritchard, R. G., Panak, P. J., Whitehead, R. C. and Harwood, L. M. (2016) Exploring electronic effects on the partitioning of actinides(III) from lanthanides(III) using functionalised bis-triazinyl phenanthroline ligands. Dalton Transactions (45). pp. 18102-18112. ISSN 1364-5447 doi: https://doi.org/10.1039/C6DT02474B Available at https://centaur.reading.ac.uk/66596/

It is advisable to refer to the publisher's version if you intend to cite from the work. See Guidance on citing.

To link to this article DOI: http://dx.doi.org/10.1039/C6DT02474B

Publisher: Royal Society of Chemistry

All outputs in CentAUR are protected by Intellectual Property Rights law, including copyright law. Copyright and IPR is retained by the creators or other copyright holders. Terms and conditions for use of this material are defined in the End User Agreement. 


\section{www.reading.ac.uk/centaur}

\section{CentAUR}

Central Archive at the University of Reading

Reading's research outputs online 


\title{
Exploring Electronic Effects on the Partitioning of Actinides(III) from Lanthanides(III) using Functionalised Bis-triazinyl Phenanthroline Lig- ands
}

\author{
Alyn C. Edwards, ${ }^{\dagger}$ Christoph Wagner ${ }^{\ddagger}, \ell$ Andreas Geist, ${ }^{\ddagger}$ Neil A. Burton, ${ }^{\dagger}$ Clint A. Sharrad, ${ }^{\Delta}$ Ralph W. Ad- \\ ams, $^{\dagger}$ Robin G. Pritchard, ${ }^{\dagger}$ Petra J. Panak, ${ }^{\ddagger, \ell}$, Roger C. Whitehead ${ }^{+*}$ and Laurence M. Harwood ${ }^{{ }^{*}}$ \\ ${ }^{\dagger}$ School of Chemistry, The University of Manchester, Oxford Road, Manchester, M13 9PL, U.K. \\ ${ }^{\ddagger}$ Karlsruher Institut für Technologie (KIT-INE), Institut für Nukleare Entsorgung, Hermann-von-Helmholtz-Platz 1, D-76344 \\ Eggenstein-Leopoldshafen, Germany. \\ ${ }^{\ell}$ University of Heidelberg, Department of Physical Chemistry, Im Neuenheimer Feld 253, 69120, Germany. \\ ${ }^{\Delta}$ School of Chemical Engineering, The University of Manchester, Oxford Road, Manchester, M13 9PL, U.K. \\ ${ }^{\S}$ Department of Chemistry, The University of Reading, Reading, RG6 6AD, U.K.
}

\begin{abstract}
The first examples of 4,7-disubstituted 2,9-bis(5,5,8,8-tetramethyl-5,6,7,8-tetrahydro-1,2,4-benzo-triazin-3-yl)-1,10phenanthroline (CyMe $\mathrm{M}_{4}$-BTPhen) ligands are reported herein. Evaluating the kinetics, selectivity and stoichiometry of actinide(III) and lanthanide(III) radiotracer extractions has provided a mechanistic insight into the extraction process. For the first time, it has been demonstrated that metal ion extraction kinetics can be modulated by backbone functionalisation and a promising new CHON compliant candidate ligand with enhanced metal ion extraction kinetics has been identified. The effects of 4,7functionalisation on the equilibrium metal ion distribution ratios are far more pronounced than those of 5,6-functionalisation. The complexation of $\mathrm{Cm}$ (III) with two of the functionalised ligands was investigated by TRLFS and, at equilibrium, species of 1:2 [M:L] stoichiometry were observed exclusively. A direct correlation between the $E_{\text {LUMO }}-E_{\text {HOMO }}$ energy gap and metal ion extraction

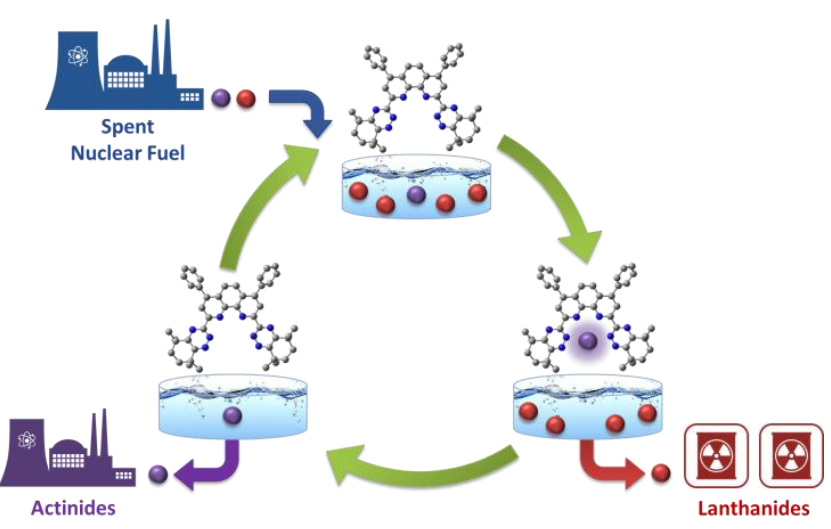
potential is reported, with DFT studies reaffirming experimental findings.
\end{abstract}

\section{INTRODUCTION}

Energy generation by nuclear fission is one of the likely key components in an energy mix that will reduce greenhouse gas (GHG) emissions while still providing sufficient energy for the world's population at a reasonable cost. ${ }^{1-3}$ Next generation nuclear fission reactors are being developed with aims to be more energy intensive and accident tolerant while maximizing the fuel resources available. ${ }^{4,5}$ Examples include the deployment of fast breeder reactors. ${ }^{2,5}$ In order to support such activity, full actinide recycle strategies are needed where the minor actinides (MA: $\mathrm{Np}, \mathrm{Am}$ and $\mathrm{Cm}$ ) are partitioned from spent nuclear fuel and made available for use as fuel in these advanced reactors. ${ }^{2,3}$ Despite only accounting for approximately 1 wt \% of spent fuel, $\mathrm{Pu}$ and the minor actinides are the main contributors to the long-term radiotoxicity and thermal power in spent nuclear fuel from most current nuclear reactors. The removal and burning of the minor actinides can significantly reduce the volume and long-term thermal and radioactive load of the highly active waste intended for disposal in a deep geological repository. ${ }^{2,6,7}$ Consequently, substantial research has been devoted to developing the non-trivial separation of the minor actinides, $\mathrm{Am}$ and $\mathrm{Cm}$, from the chemically similar lanthanides found as fission products in spent nuclear fuel by solvent extraction methods. ${ }^{8-10}$ Despite this extensive body of work which has identified extractants that can partition minor actinides from the lanthanides with separation factors between 20-2000, little is known with regards to the essential electronic and steric requirements of the molecular extractants that result in this selectivity. ${ }^{8-11}$

It has been postulated that one of the major contributors to this selectivity is the more radially extended nature of the $5 f$ actinide orbitals versus the $4 f$-lanthanide orbitals. ${ }^{12,13}$ It is believed that this subtle difference is exploited by the soft donor ligands, leading to increased ligand-actinide bond covalency and thus selectivity for the actinides. ${ }^{15} \mathrm{~N}$ NMR spectroscopic studies utilising a ${ }^{15} \mathrm{~N}$ labelled bis-triazinyl pyridine (BTP 1: Figure 1) analogue, a $N$-donor extractant that exhibits selectivity for minor actinides over lanthanides, have provided some 
of the first direct evidence for this increased degree of covalency. ${ }^{14}$ Computational studies have identified possible discrepancies with regards to the nature of covalency in actinide-ligand bonding which shows the complexity of interpreting interactions that involve the $f$-orbitals. ${ }^{15}$ Consequently, an improved understanding on how systematic changes to an extractant molecular framework impacts on minor actinide/lanthanide separations performance is needed to understand further the role of $f$-orbital covalency, if any, in such partitioning processes.

The set of extractants stemming from the initial bis-triazinyl pyridine (BTP) molecules (1, Figure 1) reported by Kolarik et al. showed considerable promise for minor actinide/lanthanides separations. ${ }^{16,17}$ Subsequently, the tetradentate BTBP (2) and BTPhen (3) ligand systems, bearing the radio- and hydrolytic tolerant $\mathrm{CyMe}_{4}$ moiety have demonstrated very promising partitioning capabilities, and have become benchmark extraction reagents for the European SANEX (Selective ActiNide EXtraction) process. $^{8-10,16-19}$ To explore the influence of electronic requirements on minor actinide/lanthanide separations we have investigated alternatives to the cis-locked 1,10 phenanthroline derived, $\mathrm{CyMe}_{4}$-BTPhen (3, Figure 1), which has relatively fast complexation kinetics and profound selectivity for the minor actinides $\left(\mathrm{SF}_{\mathrm{Am} / \mathrm{Eu}}=68-400\right)^{11,12,20}$

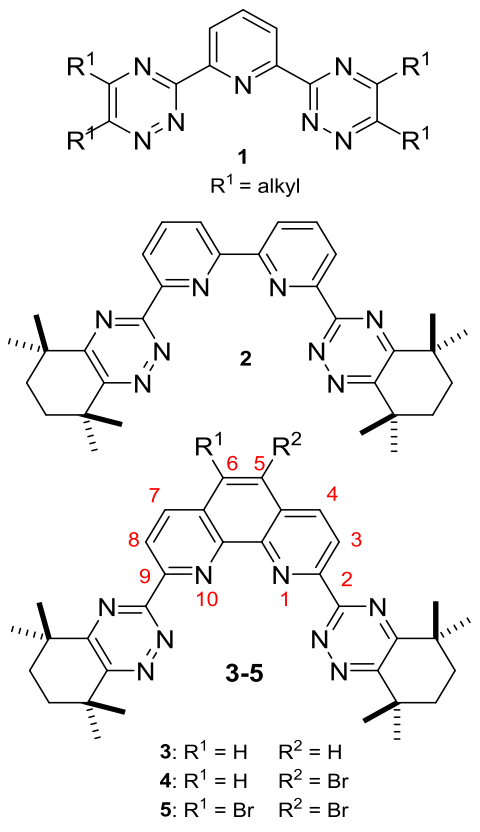

Figure 1. Molecular Structures of CyMe $\mathrm{CH}_{4}$-BTP 1, CyMe $\mathrm{C}_{4}$-BTBP 2 and $\mathrm{CyMe}_{4}$-BTPhen analogues 3-5.

Screening of the 5 and 5,6-bromo-functionalised $\mathrm{CyMe}_{4}-$ BTPhen ligands 4 and 5 (Figure 1) revealed the substantial impact that subtle electronic changes can have on the preequilibrium partitioning behaviour, providing $\mathrm{SF}_{\mathrm{Am} / \mathrm{Eu}}=250^{\ddagger}$ and $800^{\ddagger}$ respectively. ${ }^{21}$ Based on these previous findings, it was postulated that substitution at the 4,7-positions of the 1,10phenanthroline core would provide enhanced electronic modulation due to the para-positioning of the substituents to the phenanthroline $\mathrm{N}$-atoms. Herein, we report the synthesis and solvent extraction behavior of three, 4,7-disubstituted $\mathrm{CyMe}_{4}{ }^{-}$ BTPhen analogues and how electronic modulation of this extractant template impacts on minor actinide/lanthanide partitioning performance.

\section{RESULTS}

Synthesis of 4,7-disubstituted $\mathrm{CyMe}_{4}$-BTPhen analogues. To introduce the desired functionality into the 1,10phenanthroline core, the versatile intermediate 4,7-dichloro2,9-dimethyl-1,10-phenanthroline 8 was prepared using the synthetic protocol described by Ulven et al. (Scheme 1). ${ }^{22}$ Batches of intermediate $\mathbf{8}$ were functionalised with electron donating methoxy-moieties via the in situ generation of sodium methoxide (9). The introduction of a phenyl substituent was achieved using a Pd-catalysed Suzuki-Miyaura cross coupling with phenylboronic acid (10). The 4,7-diphenyl substituted compound was designed to be an intermediate between the stronger electronically modifying effects of the chloro- and methoxy-substituents. It was reasoned that this modification would also enhance solubility in hydrocarbon based solvents by reducing molecular polarity and planarity. ${ }^{23}$

To date, all reported syntheses of $\mathrm{CyMe}_{4}-\mathrm{BTPhen}(3)$ and its analogues (4-5) have involved the benzylic oxidation of commercially available neocuproine using excess $\mathrm{SeO}_{2} \cdot{ }^{20,21,24,25}$ In the hands of Ulven and colleagues, application of this oxidation procedure to substrate $\mathbf{8}$ provided an unsymmetrical oxy-chloro compound. ${ }^{22}$ These findings combined with the highly toxic nature of $\mathrm{SeO}_{2}$ and the reaction residues, rendered this particular route unsuitable for the synthesis of 4,7-Cl-CyMe ${ }_{4}-\mathrm{BTPhen}$ (33) and a new synthetic protocol was developed (Scheme 2). This alternative route was then applied to the parent $\mathrm{CyMe}_{4}-$

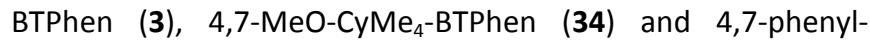
$\mathrm{CyMe}_{4}-\mathrm{BTPhen}$ (35). This alternative approach to benzylic functionalisation commenced with the per-chlorination of the two methyl groups of substrates 8-11 using excess NCS, with benzoyl peroxide (BPO) as initiator. Given that the oxidation level of the symmetrical tetra-chlorinated intermediate is equivalent to that of the bis-aldehyde, attempts were made to stop the sequence at this stage to streamline the synthetic route. Unfortunately, the symmetrical tetra-chlorinated intermediated could not be isolated and numerous different chlorinated species were obtained when the process was not allowed to reach completion. The subsequent methanolysis of intermediates 12-15 using concentrated $\mathrm{H}_{2} \mathrm{SO}_{4}$ and $\mathrm{MeOH}$ afforded bis-esters 16-19. The synthesis of bis-amides 20-23 was carried out by stirring compounds 16-19 in concentrated $\mathrm{NH}_{4} \mathrm{OH}$ at ambient temperature for 3 days. 
Scheme 1: Synthesis of 4,7-disubstituted CyMe ${ }_{4}$-BTPhen analogues.<smiles>CC1(C)OC(=O)CC1=O</smiles>

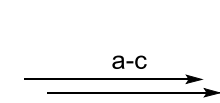<smiles>COC(C)(OC)OC</smiles><smiles>[R]c1cc(C)nc2c1ccc1c([R])cc(C)nc12</smiles><smiles></smiles>

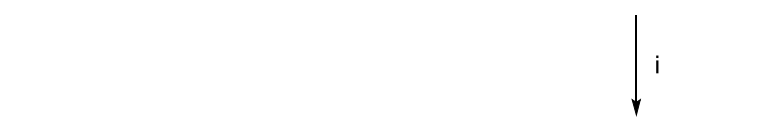<smiles></smiles>

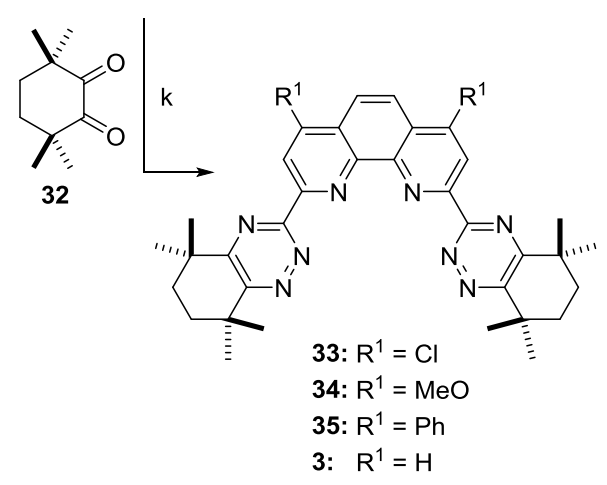

"Compound numbers follow relative trend shown for 33 -

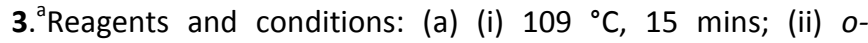
phenylenediamine, $109{ }^{\circ} \mathrm{C}, 2 \mathrm{~h}$; (iii) $25^{\circ} \mathrm{C}, 16 \mathrm{~h}, 65 \%$; (b) $\mathrm{Ph}_{2} \mathrm{O}$, $260{ }^{\circ} \mathrm{C}, 30$ mins, $95 \%$; (c) $\mathrm{POCl}_{3}, 90{ }^{\circ} \mathrm{C}, 3.5$ h, $98 \%$; (d) $\mathrm{Na}$ metal, $\mathrm{MeOH}, 65{ }^{\circ} \mathrm{C}, 72 \mathrm{~h}, 96 \%$; (e) $\mathrm{K}_{2} \mathrm{CO}_{3}, \mathrm{Pd}\left(\mathrm{PPh}_{3}\right)_{4}, \mathrm{Ph}-$ $\mathrm{B}(\mathrm{OH})_{2}, 66{ }^{\circ} \mathrm{C}, 24 \mathrm{~h}, 98 \%$. Synthesis of $4,7-\mathrm{Cl}-\mathrm{CyMe} \mathrm{M}_{4}-\mathrm{BTPhen}$ (33). Reagents and conditions: (f) (PhCOO) $)_{2}, \mathrm{NCS}, \mathrm{CHCl}_{3}, 62{ }^{\circ} \mathrm{C}$, $16 \mathrm{~h}, 93 \%$; (g) (i) $\mathrm{H}_{2} \mathrm{SO}_{4}, 95{ }^{\circ} \mathrm{C}, 1 \mathrm{~h}$; (ii) $\mathrm{MeOH}, 65{ }^{\circ} \mathrm{C}, 2 \mathrm{~h}, 66 \%$; (h) $\mathrm{NH}_{4} \mathrm{OH}(29 \%), \mathrm{NH}_{4} \mathrm{Cl}, 25^{\circ} \mathrm{C}, 72 \mathrm{~h}, 85 \%$; (i) (i) (COCl) $2, \mathrm{DMF}$, $0{ }^{\circ} \mathrm{C}, 6 \mathrm{~h}$; (ii) pyridine, $25^{\circ} \mathrm{C}, 1 \mathrm{~h}, 72 \%$; (j) $\mathrm{N}_{2} \mathrm{H}_{4} \cdot \mathrm{H}_{2} \mathrm{O}$, EtOH, $25^{\circ} \mathrm{C}$, 72 h, 84 \%; (k) 32 (2.2 eqvs), EtOH, $78{ }^{\circ} \mathrm{C}, 3$ h, $11 \%$. Synthesis of 4,7-MeO-CyMe $\mathrm{M}_{4}$-BTPhen 34. Reagents and conditions: (f) (PhCOO) $)_{2}, \mathrm{NCS}, \mathrm{CHCl}_{3}, 62{ }^{\circ} \mathrm{C}, 48 \mathrm{~h}, 95 \%$; (g) (i) $\mathrm{H}_{2} \mathrm{SO}_{4}, 110^{\circ} \mathrm{C}, 48$ h; (ii) $\mathrm{MeOH}, 65^{\circ} \mathrm{C}, 2 \mathrm{~h}, 74 \%$; (h) $\mathrm{NH}_{4} \mathrm{OH}(29 \%), \mathrm{NH}_{4} \mathrm{Cl}, 25^{\circ} \mathrm{C}$, $72 \mathrm{~h}, 81 \%$; (i) (i) $(\mathrm{COCl})_{2}, \mathrm{DMF}, 0{ }^{\circ} \mathrm{C}, 6 \mathrm{~h}$; (ii) pyridine, $25^{\circ} \mathrm{C}, 1 \mathrm{~h}$, 50 \%; (j) $\mathrm{N}_{2} \mathrm{H}_{4} \cdot \mathrm{H}_{2} \mathrm{O}, \mathrm{EtOH}, 25{ }^{\circ} \mathrm{C}, 72 \mathrm{~h}, 54 \%$; (k) 31 (2.2 eqvs), $\mathrm{EtOH}, 78{ }^{\circ} \mathrm{C}, 3 \mathrm{~h}, 34 \%$. Synthesis of 4,7-phenyl-CyMe $\mathrm{M}_{4}-\mathrm{BTPhen}$ 35. Reagents and conditions: (f) (PhCOO) ${ }_{2}, \mathrm{NCS}, \mathrm{CHCl}_{3}, 62{ }^{\circ} \mathrm{C}, 24$ h, $80 \%$; (g) (i) $\mathrm{H}_{2} \mathrm{SO}_{4}, 95^{\circ} \mathrm{C}, 2 \mathrm{~h}$; (ii) $\mathrm{MeOH}, 65^{\circ} \mathrm{C}, 1 \mathrm{~h}, 76 \%$; (h) $\mathrm{NH}_{4} \mathrm{OH}(29 \%), \mathrm{NH}_{4} \mathrm{Cl}, 25^{\circ} \mathrm{C}, 72 \mathrm{~h}, 67 \%$; (i) (i) $(\mathrm{COCl})_{2}, \mathrm{DMF}, 0{ }^{\circ} \mathrm{C}$, $6 \mathrm{~h}$; (ii) pyridine, $25^{\circ} \mathrm{C}, 1 \mathrm{~h}, 69 \%$; (j) $\mathrm{N}_{2} \mathrm{H}_{4} \cdot \mathrm{H}_{2} \mathrm{O}, \mathrm{EtOH}, 25^{\circ} \mathrm{C}, 72$ h, $77 \%$; (k) 31 (2.2 eqvs), EtOH, $78{ }^{\circ} \mathrm{C}, 3$ h, $38 \%$. Synthesis of $\mathrm{CyMe}_{4}$-BTPhen (3). Reagents and conditions: (f) Neocuproine, (PhCOO) 2 , NCS, $\mathrm{CHCl}_{3}, 62{ }^{\circ} \mathrm{C}, 72 \mathrm{~h}, 99 \%$; (g) (i) $\mathrm{H}_{2} \mathrm{SO}_{4}, 95^{\circ} \mathrm{C}, 4 \mathrm{~h}$; (ii) $\mathrm{MeOH}, 65^{\circ} \mathrm{C}, 1.5 \mathrm{~h}, 98 \%$; (h) $\mathrm{NH}_{4} \mathrm{OH}(29 \%), \mathrm{NH}_{4} \mathrm{Cl}, 25^{\circ} \mathrm{C}, 72$ h, $67 \%$; (i) (i) $(\mathrm{COCl})_{2}, \mathrm{DMF}, 0{ }^{\circ} \mathrm{C}, 6 \mathrm{~h}$; (ii) pyridine, $25^{\circ} \mathrm{C}, 0.5 \mathrm{~h}$, 54 \%; (j) $\mathrm{N}_{2} \mathrm{H}_{4} \cdot \mathrm{H}_{2} \mathrm{O}, \mathrm{EtOH}, 25^{\circ} \mathrm{C}, 72 \mathrm{~h}, 78$ \%; (k) 32 (2.2 eqvs), EtOH, $78{ }^{\circ} \mathrm{C}, 72 \mathrm{~h}, 63 \%$.

The extended reaction periods of these transformations is attributed to the insoluble nature of the substrates in concentrated aqueous $\mathrm{NH}_{4} \mathrm{OH}$. Use of elevated temperatures in sealed tubes, and increased loadings of $\mathrm{NH}_{4} \mathrm{Cl}$, failed to enhance the reaction rate. Dehydration of compounds 20-23 using the Vilsmeier-Haack reagent afforded bis-nitrile compounds 24-27 in respectable yields ( $>50 \%$ ). The penultimate step was carried out in accordance with the procedure reported by Case et al. $^{18,26,27}$ This procedure involved stirring compounds 24-27 in $\mathrm{N}_{2} \mathrm{H}_{4} \mathrm{H}_{2} \mathrm{O}$ and EtOH for 3 days at ambient temperature, providing bis-aminohydrazide compounds 28-31. The final step required the coupling of 28-31 with di-ketone $\mathbf{3 2}$ (purchased from Technocomm Ltd). ${ }^{28}$ This step proved particularly problematic with compound 28, presumably due to the electronwithdrawing nature of the chloro-substituents. When the literature procedure, involving refluxing in $\mathrm{THF}$ and $\mathrm{Et}_{3} \mathrm{~N}$, was applied to substrate $\mathbf{2 8}$, it provided $<1 \%$ of target 33 . $^{18,20,27}$ Extensive optimization efforts found that heating to reflux in EtOH for 3 hours provided a slightly improved conversion to $\mathbf{3 3}$ (11\%).

X-Ray Crystallography. Crystals suitable for the crystallographic analysis of ligand $\mathbf{3 3}$ were obtained by slow evaporation of a dichloromethane solution. As can be seen from the resulting crystal structure (Figure 2), a water molecule is present in the cavity of the ligand. This observation is consistent with the first reported X-ray crystal structure of a $\mathrm{CyMe}_{4}$ BTPhen ligand system. ${ }^{20}$ One major difference between the two structures is that ligand $\mathbf{3 3}$ was found to be in the $c-c$ conformation whereas $\mathbf{3}$ was observed in the $t$ - $t$ conformation (with regards to the two triazine rings). ${ }^{29} \mathrm{~A}$ second major difference between the structures is that the cavity of ligand $\mathbf{3 3}$ also contains a dichloromethane molecule, which was found to form non-conventional hydrogen bonds to nitrogen atoms (19) and (33). Analysis of the structure, also highlighted the non-planar geometry of ligand 32, with the N(1)-C-C-(N12) and N(10)-C-C$\mathrm{N}(26)$ torsion angles being measured as $-154.7(6)^{\circ}$ and $165.5(6)^{\circ}$ respectively, facilitating the hydrogen bonding. 


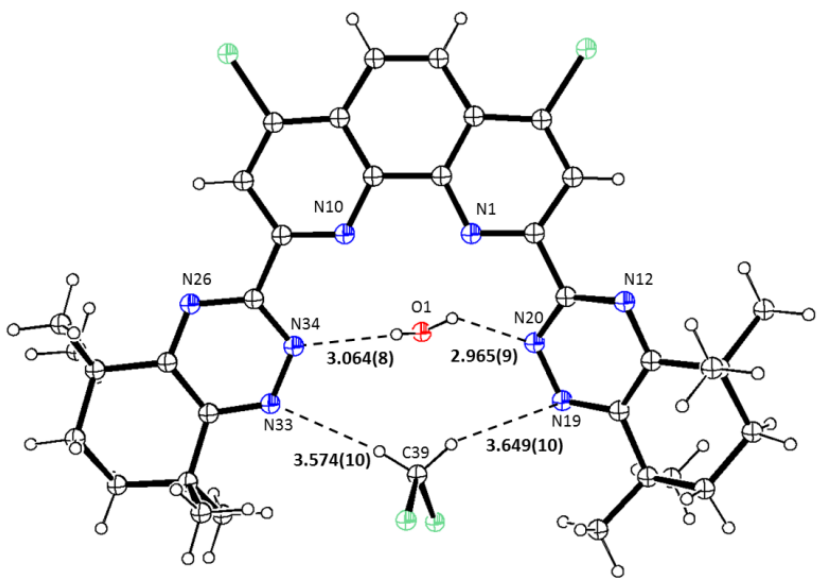

Figure 2. X-ray crystallographic structure of 4,7-Cl-CyMe4-BTPhen (33) (c-c conformer). Thermal ellipsoids are shown at $30 \%$ probability. Additional solvent molecules are omitted for clarity. Proposed hydrogen bonds are represented by dotted lines and bond distances are quoted in $\AA$.

pKa Measurements. The pKa values of ligands 3, 33 and $\mathbf{3 4}$ were determined by exploring the acid dependence of the ${ }^{1} \mathrm{H}$ NMR spectra in methanol. All three compounds exhibited very limited solubilities in a range of water containing binary and ternary solvent mixtures, e.g. $\mathrm{D}_{2} \mathrm{O}$ : MeOD (v:v) therefore, definitive pKa values could not be determined. The compounds were however, sufficiently soluble in methanol to allow "methanolic" pKa values to be determined using a modified procedure to that reported by Harwood et al. for parent $3 .^{20}$ Unfortunately, the solubility of ligand $\mathbf{3 5}$ in methanol was too low to yield the necessary spectroscopic data. The chemical shift dependence of the aromatic reporter protons in compounds $\mathbf{3}$, 33 and $34(0.2 \mathrm{mM})$ on pD were recorded following potentiometric titration (full experimental details can be found in the Supporting Information). The resulting data sets were analysed using two different approaches, the results of which are summarised in Table 1.

Table 1. pKa values of compounds 3 and 33-34 in $d_{4}$-methanol at $298 \mathrm{~K}$.

\begin{tabular}{ccccc} 
Ligand & $\begin{array}{c}\text { Reporter } \\
\text { Protons }^{\text {a }}\end{array}$ & $\begin{array}{c}\text { Inflection } \\
\text { Point }\end{array}$ & H-H & Mean \\
\hline 33 & 5,6 and 3,8 & 1.7 & 1.7 & $\mathbf{1 . 7}$ \\
$\mathbf{3}$ & 5,6 & 2.4 & 2.5 & $\mathbf{2 . 5}$ \\
$\mathbf{3 4}$ & 5,6 and 3,8 & 3.9 & 3.9 & $\mathbf{3 . 9}$ \\
\hline
\end{tabular}

${ }^{a}$ Numbering scheme in Figure 1. ${ }^{b}$ Determined by HendersonHasselbalch analysis

The first of these approaches involved plotting the observed chemical shifts $(\delta)$ against the measured $p D$, yielding a sigmoidal plot that was subsequently treated to non-

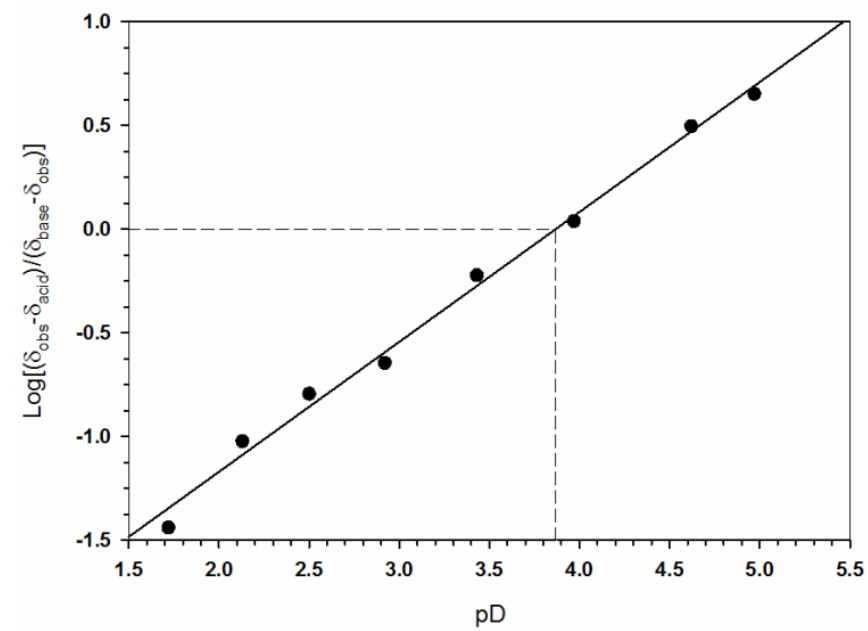

Figure 3. Application of equation 1 to the recorded chemical shifts of the 5,6 and 3,8 protons of 34 vs. pD. $r^{2}=0.9934$.

linear curve fitting. Determining the inflection point of the resulting sigmoidal curves provided the methanolic $p K a$ values of the ligands. ${ }^{30}$

The second approach involved logarithmic analysis using the Henderson-Hasselbalch approximation. The relationship between the $\mathrm{pH}$ and chemical shift $(\delta)$ expressed by this approximation is shown in equation $1 .^{31-33}$ The $x$-axis intercept of the linear, double logarithmic plots was recorded as the first pKa values of the ligands. The resulting plot for compound $\mathbf{3 4}$ is shown in Figure 3 , with the $\mathrm{x}$-axis intercept providing a pKa value of $\approx 3.9$. The plots for ligands $\mathbf{3}$ and $\mathbf{3 3}$ are provided in the Supporting Information. ${ }^{34}$

$$
\mathrm{pH}=\mathrm{pKa}+\log \frac{[\delta(\max )-\delta(\mathrm{obs})]}{[\delta(\mathrm{obs})-\delta(\min )]}
$$

As anticipated during the design of these electronically modified systems, the 4,7-methoxy-substituents were found to increase basicity by $\approx 1.4$ orders of magnitude versus 3 . Conversely, the 4,7-chloro-substituents reduced basicity by $\approx 0.8$ orders of magnitude, showing that overall basicity within the series, increases in the order $\mathbf{3 3}<\mathbf{3}<<\mathbf{3 4}$. This trend is in good agreement with that reported for the 4-functionalised BTP series in ethanol by Trumm et al. ${ }^{35}$

Both analytical methodologies provided very similar data sets with differences of $\leq 0.1$ pKa units observed. Furthermore, reasonable agreement with the literature value of parent compound 3 (2.5 vs 3.1) was achieved, despite the literature methodology not accounting for the likely change in solution pD upon dissolution of the ligand. ${ }^{20}$

Solvent Extraction Studies. Extraction capabilities were assessed by measuring the extraction kinetics and $\mathrm{HNO}_{3}$ dependence of ligands 33-35 at equilibrium. To allow for direct comparison with existing literature, parent ligand $\mathbf{3}$ was also evaluated. All of the two phase extraction experiments were implemented using solutions of ligands 3 and 33-35 in 1-octanol $(0.0045-0.01 \mathrm{M})$ and tracer quantities of ${ }^{241} \mathrm{Am}$ and ${ }^{152} \mathrm{Eu}$, and each $5 \mathrm{mg} / \mathrm{L}$ of all the lanthanides ( $\mathrm{La}(\mathrm{III})-\mathrm{Lu}$ (III) excluding 
Pm(III)) and $\mathrm{Y}(\mathrm{III})$ in $\mathrm{HNO}_{3}$. Following contact on an orbital shaker $\left(2500 \mathrm{~min}^{-1}, T=20^{\circ} \mathrm{C}\right)$ and phase separation, the distribution ratios $\left(\mathrm{D}_{\mathrm{M}(\mathrm{III})}=[\mathrm{M}(\mathrm{III})]_{\mathrm{org}} /[\mathrm{M}(\mathrm{III})]_{\mathrm{aq}}\right)$ and separation factors $\left(\mathrm{SF}_{\mathrm{Am} / \mathrm{Eu}}=\mathrm{D}_{\mathrm{Am}(\mathrm{III})} / \mathrm{D}_{\mathrm{Eu}(\mathrm{III})}\right)$ were calculated for each instance. Full experimental details are provided in the Supporting Information.

Kinetic Studies. The metal ion extraction kinetics of ligands $\mathbf{3}$ and 33-35 were investigated through a series of experiments using $0.5 \mathrm{~mL}$ of each phase with contact times of between 0.5 16 hours. Previous studies have reported ligand 3 to display enhanced metal ion extraction kinetics at increased $\mathrm{HNO}_{3}$ concentrations. ${ }^{20}$ In order to explore the impact of the various ligand substituents on extraction kinetics, an aqueous $\mathrm{HNO}_{3}$ phase concentration of $0.1 \mathrm{M}$ was selected. The $D_{c}$ values calculated from $y$-spectroscopy measurements are shown as a function of time in Figure 4. Each experiment was carried out in duplicate and the relevant ICP-MS data for all of the Ln(III) species can be found in the Supporting Information.

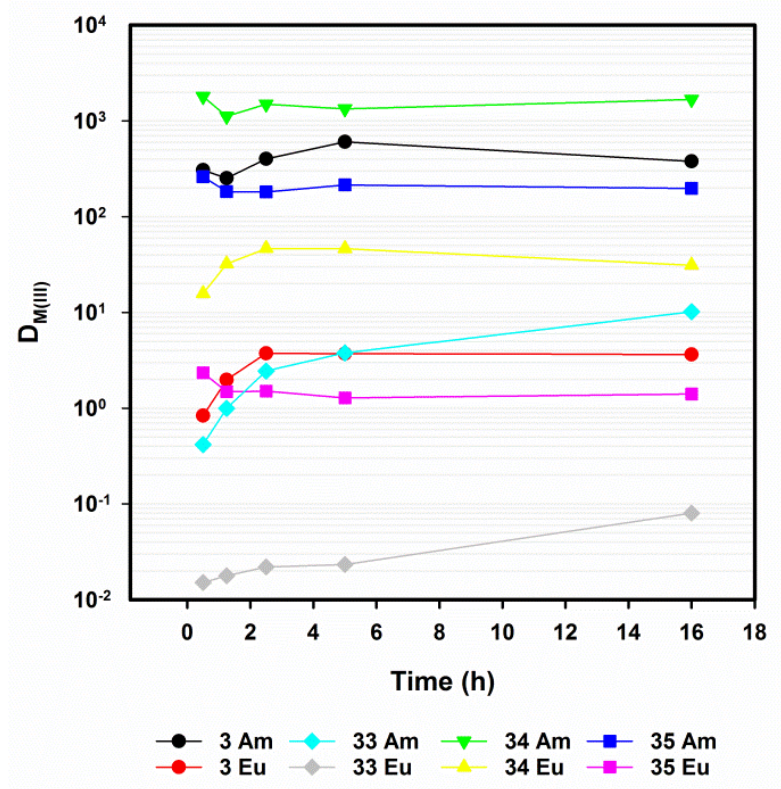

Figure 4. Distribution ratios from the extraction of $\mathrm{Am}$ (III) and $\mathrm{Eu}(\mathrm{III})$ from $0.1 \mathrm{M} \mathrm{HNO}_{3}$ by ligands 3, 33, 34 (0.01 M) and 35 $(0.0045 \mathrm{M})$ in 1-octanol as a function of contact time. Each experiment was shaken at $2500 \mathrm{~min}^{-1}$ at $20^{\circ} \mathrm{C}$.

Analysis of the obtained distribution ratios (Figure 4) showed that diphenyl system (35) had attained equilibrium within 1 hour, whilst both the parent and 4,7-dimethoxy compounds (3 and 34 respectively) took twice as long, requiring approximately 2.5 hours of contact time; whereas even after 16 hours, it was apparent that the 4,7-dichloro compound (33) had still not attained equilibrium. These results provide the first evidence that metal ion extraction kinetics of ligand $\mathbf{3}$ can be modulated by functionalisation of the 1,10-phenanthroline core, paving the way for future rationale design. Figure 4 also highlights the significant impact 4,7-functionalisation has on the equilibrium distribution ratios, with 3 orders of magnitude difference observed between $33\left(D_{A m} \approx 1.9\right)$ and $34\left(D_{A m} \approx 1800\right)$, with 33 showing very poor extraction properties and kinetics.
Acid Dependence Studies. In contrast to both the BTP (1) and BTBP ligand series (2), the extraction of Am(III) and Eu(III) by ligand $\mathbf{3}$ has been found to exhibit little dependence on $\mathrm{HNO}_{3}$ concentration. ${ }^{8,20}$ To determine whether this counterintuitive behavior was true for all $\mathrm{CyMe}_{4}-\mathrm{BTPhen}$ analogues, several acid dependency experiments were implemented using ligands 33-35. Once again, ligand $\mathbf{3}$ was studied as a 'standard'. The distribution ratios from the $\gamma$-spectroscopy and ICP-MS measurements are shown in Figures 5a-d.

The results of the $\mathrm{HNO}_{3}$ dependence study using parent ligand 3 (Figure $5 \mathrm{a}$ ), are in good agreement with previous literature as no dependence of $D_{A m}$ and $D_{E u}$ on acid concentration was observed. The measured $\mathrm{SF}_{\mathrm{Am} / \mathrm{Eu}} \approx 120$ is also in good agreement with that of the literature. ${ }^{20}$ Analysis of the $\operatorname{Ln}(\mathrm{III})$ distribution ratios show that the late-mid to early-heavy ( $\mathrm{Tb}(\mathrm{III})-\mathrm{Ho}(\mathrm{III})$ ) species are preferentially extracted, with lower distribution ratios observed for the light and late-heavy species. Very good agreement between the $\gamma$-spectroscopy and ICP-MS distribution ratios for Eu(III) was also achieved. Conversely, for ligand $\mathbf{3 4}$ it can be seen that the presence of the electron donating methoxy-substituents at the 4,7-positions appears to induce an acid dependence (Figure $5 \mathrm{~b}$ ). In this instance, almost an order of magnitude decrease in the distribution ratios was observed for all metallic species as the $\mathrm{HNO}_{3}$ concentration increased from 0.1 to $3.0 \mathrm{M}$. This observation may be attributed to the increased basicity of $\mathbf{3 4}$, resulting in increased ligand protonation and decreased free ligand concentration. Similarly to ligand 3, separation factors $\left(\mathrm{SF}_{\mathrm{Am} / \mathrm{Eu}}\right)$ of $\approx 120$ were recorded. Comparable trends in the $\operatorname{Ln}(\mathrm{III})$ distributions to those of $\mathbf{3}$ were also observed.

Interestingly, it can be seen from Figure $5 c$ that ligand $\mathbf{3 3}$ also has a dependence on $\mathrm{HNO}_{3}$ concentration. In this instance, an order of magnitude increase in the distribution ratios was witnessed as the aqueous phase $\mathrm{HNO}_{3}$ concentration was increased to $3 \mathrm{M}$. It is postulated that this may be a result of the 4,7-chloro substituents decreasing the basicity of the 1,10phenanthroline core $\mathrm{N}$-atoms, thus decreasing the extent of the competing protonation. Comparison of Figures $5 \mathrm{a}, 5 \mathrm{~b}$ and $5 \mathrm{c}$ highlights the substantial impact the 4,7-substituents have on the magnitude of the distribution ratios, with $\mathbf{3 3}$ having significantly reduced affinity for all of the trivalent species. Very little change in the selectivity of $\mathbf{3 3}$ versus $\mathbf{3}$ was recorded with the $\mathrm{Am}$ (III)/Eu(III) separation for $\mathbf{3 3} \approx 110$. The $\mathrm{Ln}$ (III) distribution ratios shown in Figure $5 \mathrm{~d}$ vary slightly to those observed for ligands $\mathbf{3}$ and $\mathbf{3 3}$ as $\mathbf{3 5}$ appears to have increased relative affinity for the lighter Sm(III) and Eu(III) species.

The solubility of $\mathbf{3 5}$ in 1-octanol was found to be limited and so a $4.5 \mathrm{mM}$ stock solution was prepared (versus $10 \mathrm{mM}$ for 3 , 33 and 34). Moreover, the addition of small quantities of kerosene $(\leq 20 \%)$ was found to increase the solubility of $\mathbf{3 5}$ substantially. The extraction behavior of ligand $\mathbf{3 5}$ was largely found to mirror that of parent compound 3, exhibiting no overall $\mathrm{HNO}_{3}$ dependence (Figure 5d). 
a)

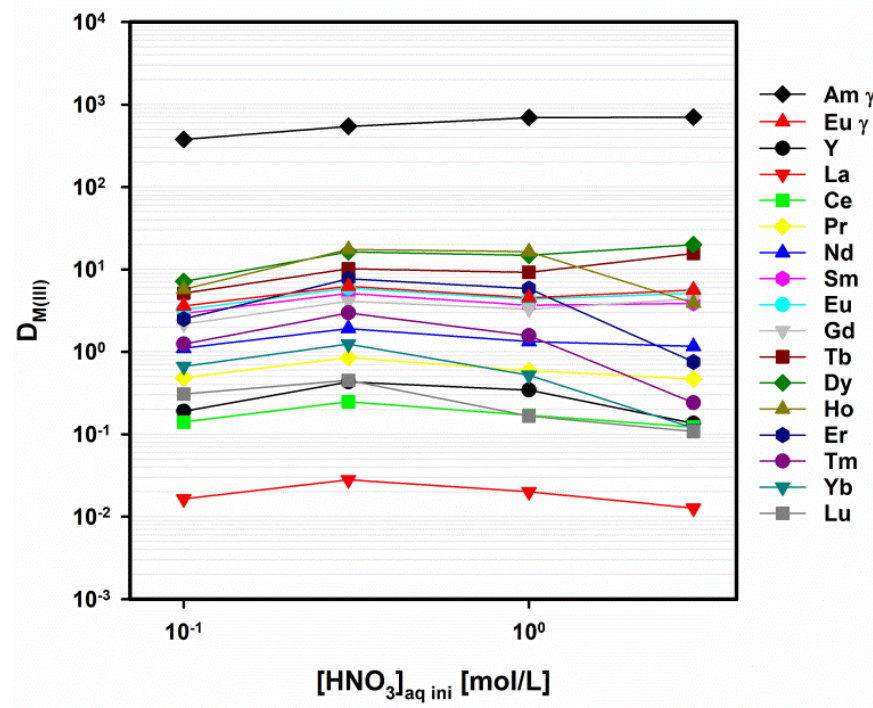

c)

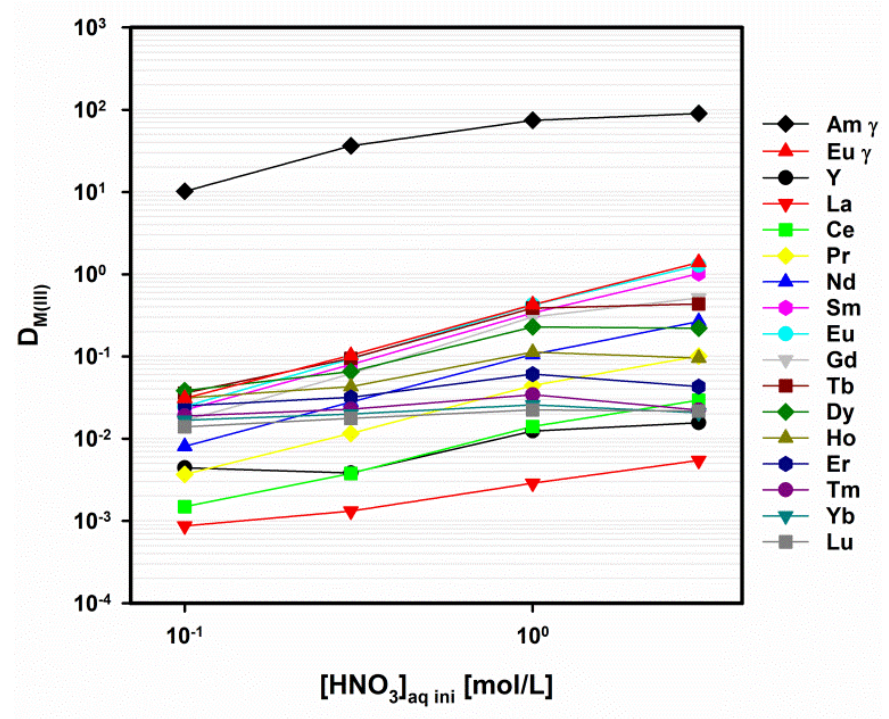

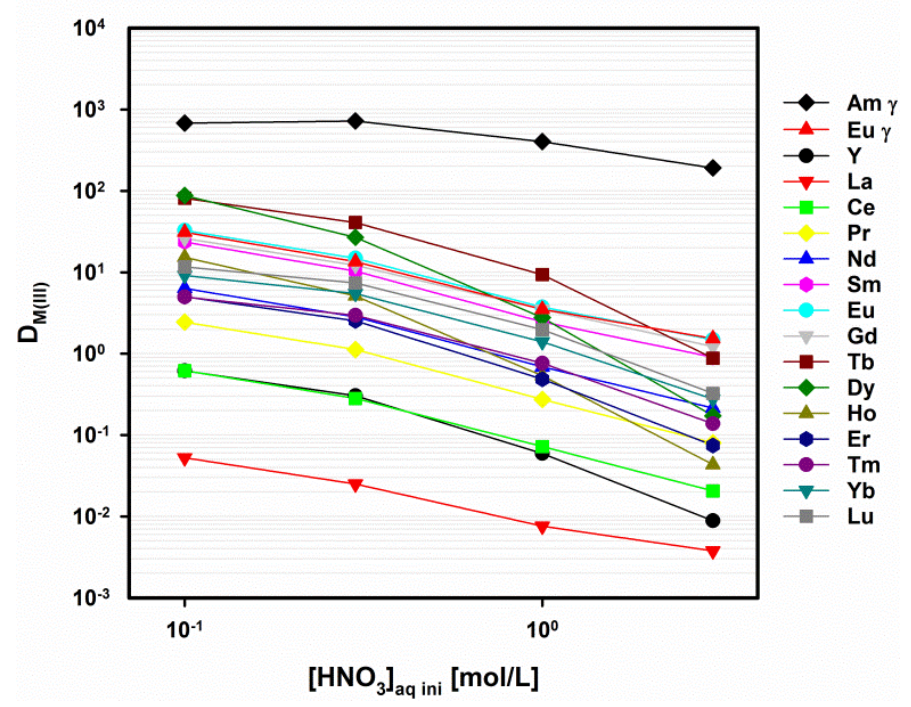

d)

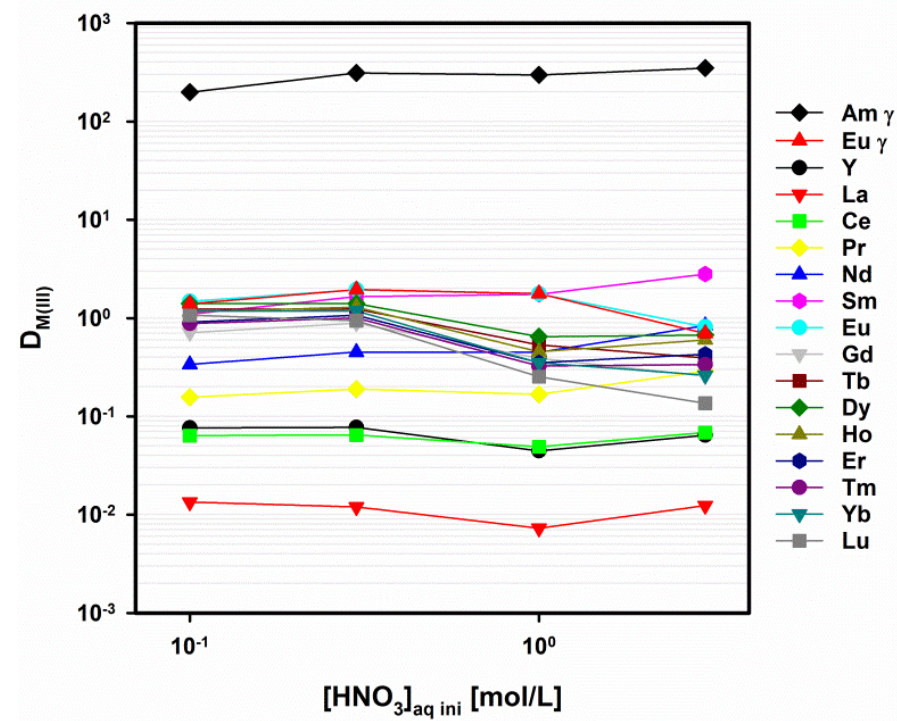

Figure 5. Distribution ratios from the extraction of $\mathrm{Am}$ (III), Eu(III), Y(III) and all of the lanthanides (La(III)-Lu(III)) excluding Pm(III) by 3 (0.01 M) (a), $34(0.01 \mathrm{M})(\mathrm{b}), 33(0.01 \mathrm{M})(\mathrm{c})$ and $35(0.0045 \mathrm{M})(\mathrm{d})$ in 1-octanol as a function of $\mathrm{HNO}_{3}$ concentration. Shaken at 2500 min ${ }^{-1}$ for 20 hours at $20^{\circ} \mathrm{C}$ and duplicated.

The magnitudes of the distribution ratios were also comparable to 3. Given its $\mathrm{CHON}$ compliant composition and faster extraction kinetics (Figure 4), $\mathbf{3 5}$ is a promising new candidate for an $\mathrm{Am}(\mathrm{III}) / \mathrm{Eu}(\mathrm{III})$ partitioning process.

Time Resolved Laser-Induced Fluorescence Spectroscopy (TRLFS) Studies. The first X-ray crystal structure of a $\mathrm{CyMe}_{4-}$ BTPhen complex was reported to be of $\left[\mathrm{Eu}(3)_{2} \mathrm{NO}_{3}\right]^{2+}$ stoichiometry, with the presence of a nitrate ion in the inner coordination sphere of the metal centre. ${ }^{20}$ This finding was later reaffirmed in 2013 by Bremer et al. using Time Resolved Laser Fluorescence Spectroscopy (TRLFS). ${ }^{36}$ To probe the complexation kinetics and solution phase stoichiometry of the disubstituted $\mathrm{CyMe}_{4}$-BTPhen analogues, a series of mono-phasic experiments using $\mathrm{Cm}$ (III) and ligands $\mathbf{3 3}$ and $\mathbf{3 4}$ in EtOH was studied using TRLFS. The fluorescence spectra presented in Figure 6 are a result of the ${ }^{6} D^{\prime}{ }_{7 / 2} \rightarrow{ }^{8} \mathrm{~S}_{7 / 2}^{\prime}$ transition over time.

For comparative purposes, all spectra are normalised to the same peak area. Full experimental TRLFS details can be found in the Supporting Information. Figure 6a shows the normalised $\mathrm{Cm}$ (III) emission spectra from $\mathrm{Cm}\left(\mathrm{ClO}_{4}\right)_{3}\left(1.0 \times 10^{-7} \mathrm{M}\right)$ after the addition of 3.3 equivalents of $\mathbf{3 3}$ as a function of time. Initially three emission bands are observed. 


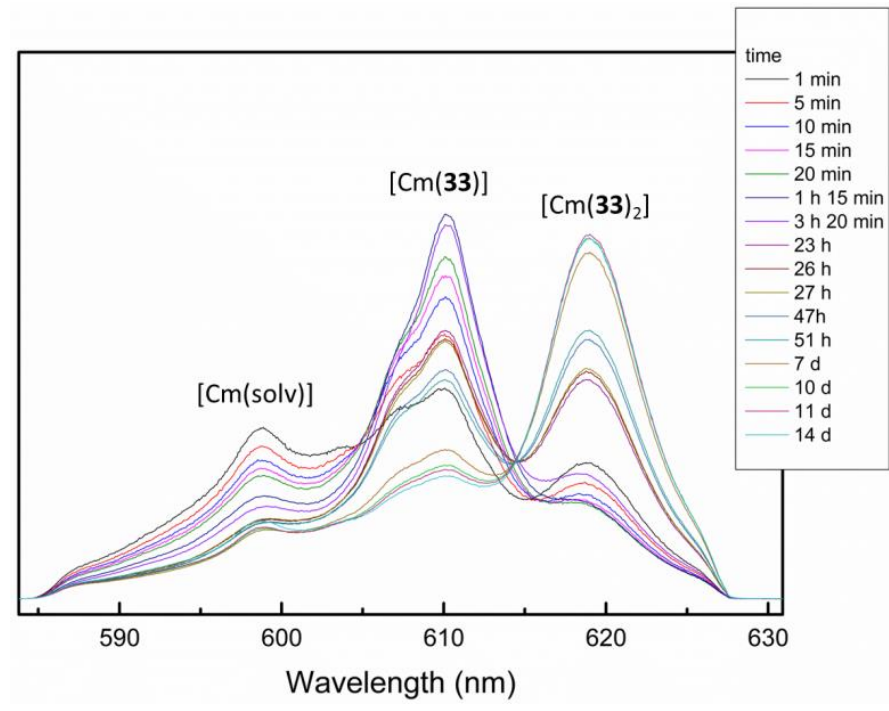

a)

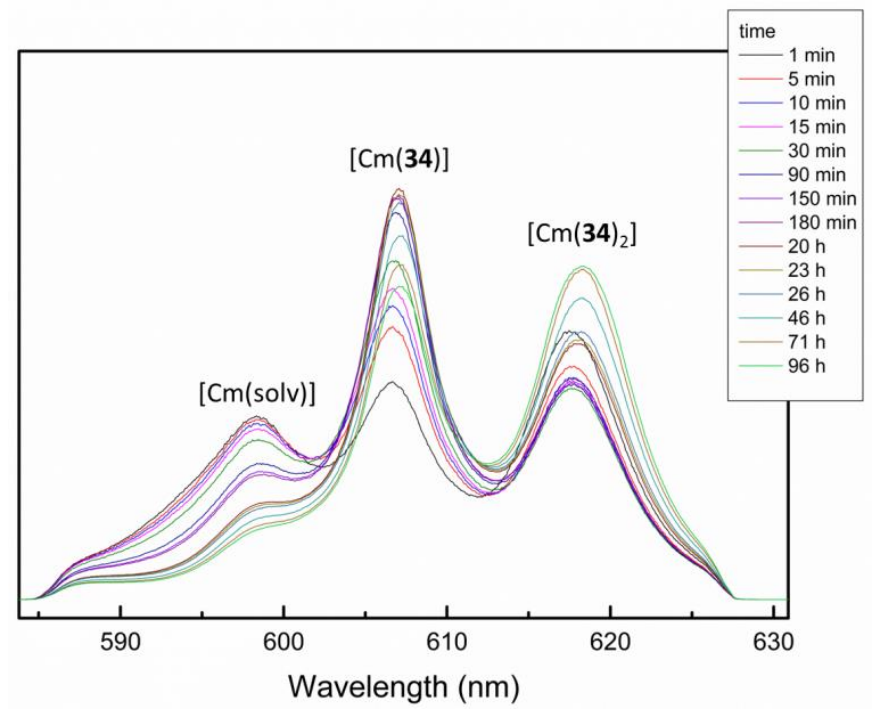

b)

Figure 6: Evolution of the normalised fluorescence spectra of the $\mathrm{Cm}(\mathrm{III})-\mathbf{3 3}$ (a) and $\mathrm{Cm}$ (III)-34 (b) complexes over time. Spectra were obtained in EtOH containing 2 mol\% ultrapure $\mathrm{H}_{2} \mathrm{O}$ (Millipore, Billerica, USA; $\left.18.2 \mathrm{M} \Omega \mathrm{cm}\right),\left(\mathrm{c}(\mathrm{Cm}(\mathrm{III}))=1.0 \times 10^{-7} \mathrm{M}\right)$ and $\left(\mathrm{c}(33)=3.3 \times 10^{-7}\right.$ $\mathrm{M})$ or $\left(\mathrm{c}(34)=2.0 \times 10^{-7} \mathrm{M}\right)$.

The emission band with a maximum at $599.0 \mathrm{~nm}$ can be attributed to the solvated $\mathrm{Cm}$ (III) species. The red shift of the emission bands to $609.9 \mathrm{~nm}$ and $619.2 \mathrm{~nm}$ result from a large ligand field splitting due to the complexation of $\mathrm{Cm}$ (III) with $\mathbf{3 3}$ and are characteristic for 1:1 and 1:2 [M:L] complex species of $\mathrm{Cm}$ (III) with BTPhen type ligands, respectively. ${ }^{36-38}$ Only 1 min after addition of $\mathbf{3 3}$ the emission bands of the solvent species and the 1:1 [M:L] complex show similar intensities with a less prominent emission band corresponding to the $1: 2[\mathrm{M}: \mathrm{L}] \mathrm{com}-$ plex. For the first 3 hours, the relative intensities of both the $[\mathrm{Cm}($ solv. $)]$ and $\left[\mathrm{Cm}(33)_{2}\right]$ emissions decreased whilst the $[\mathrm{Cm}(33)]$ peak increased. After this period, a substantial increase in the intensity of the $\left[\mathrm{Cm}(33)_{2}\right]$ emission was observed over a period of 11 days. Comparison of the spectra after 11 and 14 days suggested that the system had finally reached equilibrium. This 11 day equilibration period is extremely slow, with 3 reported to have reached equilibrium after approximately 24 hours. $^{36}$

Similar observations to those obtained with $\mathbf{3 4}$ were noted for 33 , with initially high concentrations of $[\mathrm{Cm}(34)](606.8 \mathrm{~nm})$ decreasing to form $\left[\mathrm{Cm}(34)_{2}\right](618.2 \mathrm{~nm})$ complex Figure $6 \mathrm{~b} . \mathrm{In}$ this instance, the system took approximately 3 days to reach equilibrium; which is significantly faster than analogue $\mathbf{3 3}$ but slower than 3.

The kinetic experiments were performed at very low ligand concentrations $\left(\approx 10^{-7} \mathrm{M}\right)$ in order to observe changes in the species distribution. Analogous TRLFS experiments using ligand concentrations likely to be used in extraction processes $\left(\approx 10^{-2}\right.$ $\mathrm{M})$ resulted in the 1:2 [M:L] complex being observed exclusively. Therefore, mono-phasic TRLFS experiments highlight that both ligands $\mathbf{3 3}$ and $\mathbf{3 4}$ preferentially form complexes of 1:2 [M:L] stoichiometry with $\mathrm{Cm}(\mathrm{III})$. To verify this observed stoichiometric preference, a series of extraction experiments utilising varying concentrations of $\mathbf{3}$ and 33-35 was implemented. Determining the slopes of resulting double logarithmic plots validated that complexes of 1:2 [M:L] stoichiometry are formed preferentially (see Supporting Information). Both of these data sets are in agreement with the findings of Bremer et al. for parent compound $\mathbf{3}^{36}$

Computational studies of free ligands. The conformational preferences of parent $\mathbf{3}$ have been intensively studied at the DFT level of theory, with the $c$-c conformer being reported as the most favorable (by $\approx 4.1 \mathrm{kcal} \mathrm{mol}^{-1}$ ). ${ }^{39}$ This conformational preference is consistent with that observed in the crystallographic structure of $\mathbf{3 3}$ (Figure 2). In order to explore the theoretical effects of 4,7-functionalisation on the electronic structure and potential for metal binding, the lowest energy, $c-c$ conformers of ligands $\mathbf{3}$ and 32-35 were optimised using DFT using the B3LYP exchange-correlation functional and the 6$31 \mathrm{G}(\mathrm{d})$ basis set. Proton affinities (PA), natural atomic charges and orbital energies ( $E_{\text {HOMO }}$ and $E_{\text {LUMO }}$ ) were computed for these structures at the higher B3LYP/6-311G(2d,p) level.

Proton Affinities. Proton affinities $\left(E_{\text {prot }}\right)$ in the gas phase are commonly used to quantify ligand basicity in preference to $\mathrm{pKa}$ values where solvation effects are influential. ${ }^{40-43}$ In this instance, the $E_{\text {prot }}$ values of $\mathbf{3}$ and 33-35 were calculated from the relative differences in energies of the protonated and unprotonated species in the $c-c$ conformations. In accord with the obtained experimental data (see pKa measurements), the $E_{\text {Prot }}$ of compound $\mathbf{3 4}$ was found to be the most favorable of the series $\left(-276.1 \mathrm{kcal} \mathrm{mol}^{-1}\right)$, followed by $\mathbf{3 5}$ and parent $\mathbf{3}(-273.2$ and $\left.-267.9 \mathrm{kcal} \mathrm{mol}^{-1}\right)$ respectively. The 4,7-chloro compound 33 was found to be the least favorable with $E_{\text {prot }}=-263.3 \mathrm{kcal}$ $\mathrm{mol}^{-1}$. These values are also in good agreement with those reported by Benay et al. for $\mathrm{CyMe}_{4}$-BTPhen (3) and 4-t-Bu$\mathrm{CyMe}_{4}$-BTPhen (-271.3 and $-275.4 \mathrm{kcal} \mathrm{mol}^{-1}$ respectively). ${ }^{41}$ 


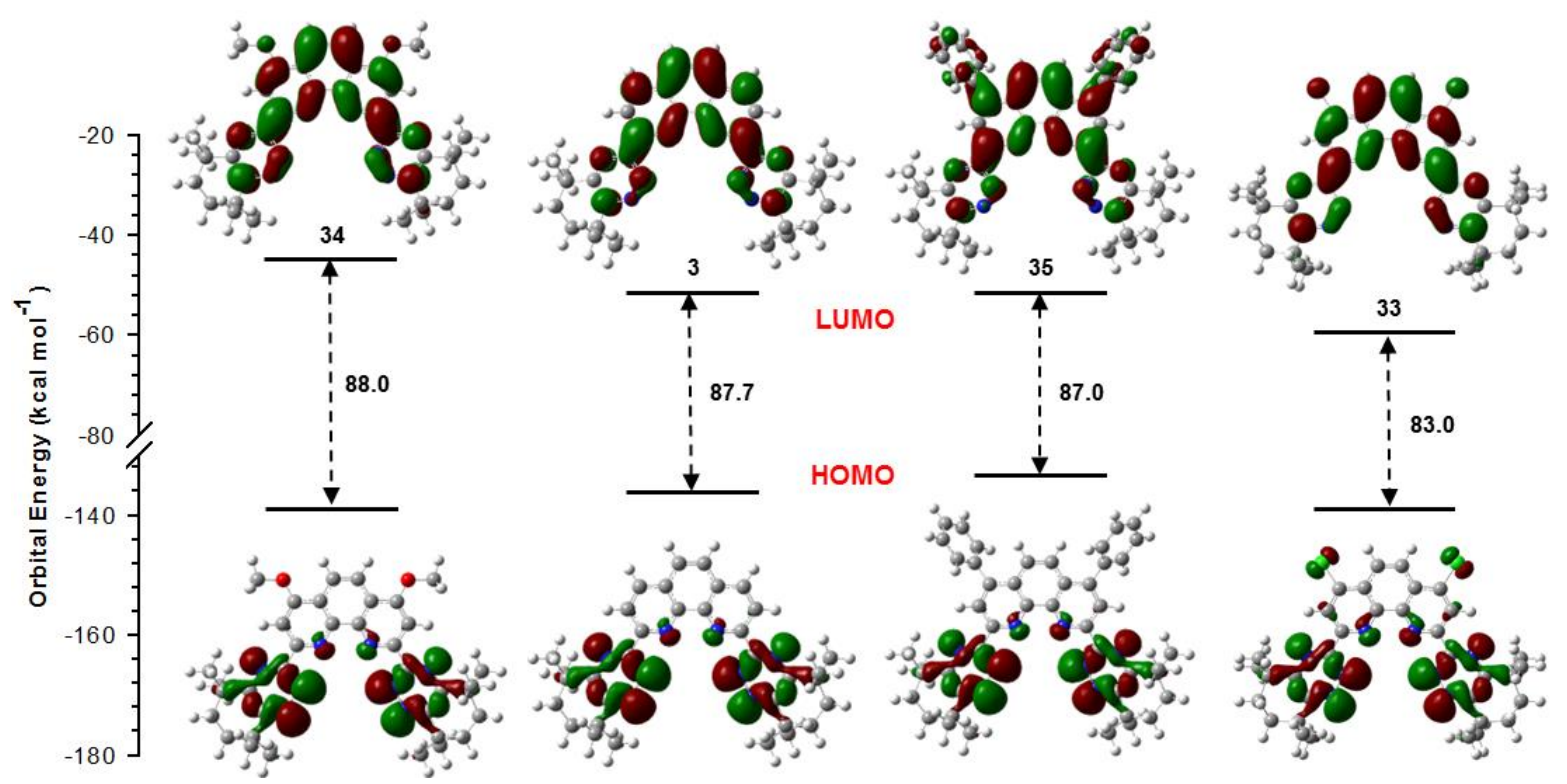

Figure 7: Walsh diagram for ligands $\mathbf{3}$ and 33-35 in the $c$-c conformations, showing the frontier orbitals and their relative energies.

It is well established that ionisation equilibrium is largely dependent on the polarity and ion-solvating ability of the surrounding solvent. ${ }^{41,44,45}$ To assess the influence (if any) of such effects on the proton affinities of $\mathbf{3}$ and 33-35, the DFT calculations were re-executed using the polarisable continuum solvation model (PCM) to include the effects of the aqueous environment $\left(E_{\text {Prot-Water }}\right)$. It was rationalized that any effects would be most significant in highly polar media such as water and less so for moderately-polar media such as 1-octanol; thus calculations in water were selected to provide the full extent of such effects. In the case of ligands $\mathbf{3}$ and 33-35, only changes in the absolute $E_{\text {Prot-Water }}$ values c.f. $E_{\text {prot }}$ were observed, with the relative trend in the $E_{\text {prot-Water }}$ values remaining unchanged: $33<3<35<34$.

Frontier Orbital Analysis. The frontier orbital energies of ligands 3 and 33-35 in the c-c conformation were calculated. Analysis of the resulting orbital depictions (Figure 7) revealed that 4,7-functionalisation has only a very subtle effect on the occupation of the HOMO and LUMO orbitals. In each case, the HOMO is largely occupied by the lone pair electrons of the triazine $\mathrm{N}$-atoms, with a small contribution from the lone pair of the phenanthroline $N$ atoms. Conversely, the LUMO in each was found to be evenly contributed to, by both the 1,10phenanthroline core and adjacent triazine rings. These observations are in excellent agreement with those reported by Lewis et al. and reinforce that the triazine $N$-atoms play a dominant role in the donation of electrons to $\mathrm{M}^{3+}$ ions. ${ }^{39}$

Evaluating the HOMO-LUMO energy gaps, $\Delta \mathrm{E}=E_{\mathrm{LUMO}}-E_{\mathrm{HOMO}}$, of ligands $\mathbf{3}$ and 33-35 (Figure 7), directly reveals the impact 4,7-functionalisation has on the chemical hardness of the ligand. ${ }^{46-49}$ Despite the calculated changes between parent 3 and 34-35 being relatively modest $\left(\approx 0.9 \mathrm{kcal} \mathrm{mol}^{-1}\right)$, considerable differences were observed between the softest ligand $\mathbf{3 3}$ and the hardest ligand $\mathbf{3 4}\left(5 \mathrm{kcal} \mathrm{mol}^{-1}\right)$. The magnitude of this difference is analogous to that reported for the $\mathrm{Me}_{2}$ (t-bipy) and $\mathrm{Me}_{2}$ (t-phen) compounds by Mohapatra et al. ${ }^{42}$
These energy gaps can be compared with the metal ion distribution ratio $\left(D_{c}\right)$ values at low acid concentration, in order to correlate the hardness with the metal binding potential of the ligand. We used the $\ln \left(D_{c}\right)$ values, recognizing the exponential relationship between equilibrium and energy difference, at the lowest experimental $\mathrm{HNO}_{3}$ concentration of $0.1 \mathrm{~mol} \mathrm{~L}^{-1}$, thus minimising the dependence due to the ligand-acid equilibrium (Figure 8).

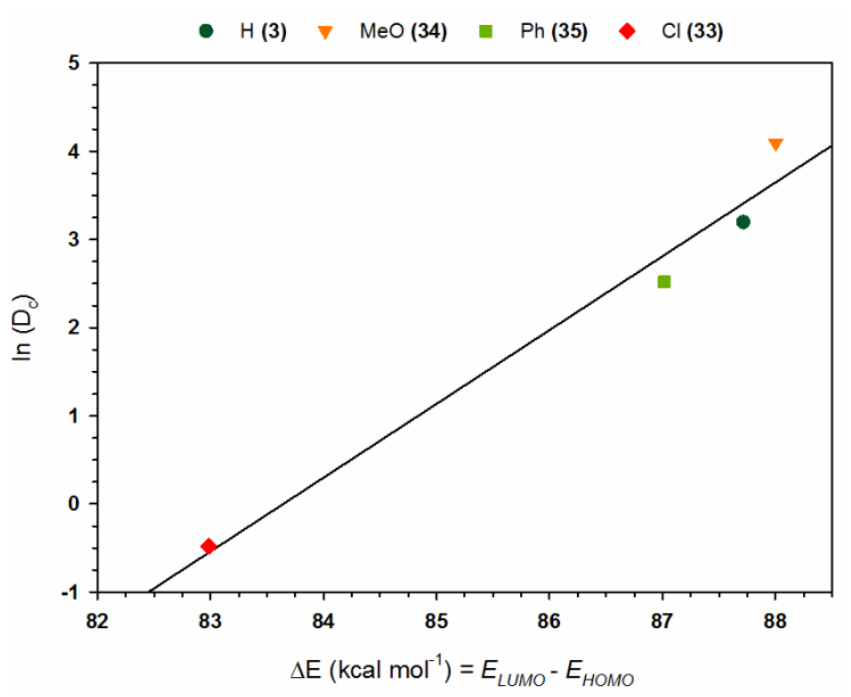

Figure 8: Plot of the averaged $D_{c}$ values of ${ }^{241} \mathrm{Am},{ }^{152} \mathrm{Eu}$ and all of the lanthanides (La(III)-Lu(III) excluding Pm(III)) and Y(III) vs. frontier orbital energy gap for ligands 3 and 33-35. $r^{2}=0.9713$. (dark green circle $=\mathbf{3}$, orange triangle $=\mathbf{3 4}$, green square $=\mathbf{3 5}$ and red diamond $=33$ ).

Natural Atomic Charge Analysis. To examine the electronic impact of 4,7-functionalisation on the BTPhen framework further, natural bond orbital (NBO) analysis was performed. The natural atomic charges (Table 2 ) resulting from this analysis confirmed that functionalisation of the 1,10-phenanthroline 
core largely impacts the electron density of the metalcoordinating phenanthroline $\mathrm{N}$-atoms, with only small changes in the triazine rings recorded. The results also correlate with the experimentally measured $D_{c}$ values, with ligand $\mathbf{3 4}$ having the largest total electron density $(-2.664)$ and $D_{c}$ values $\left(D_{A m} \approx\right.$ 700) whilst 33 was found to have the lowest theoretical electron density $(-2.602)$ and $D_{C}$ values $\left(D_{A m} \approx 10\right)$.

Table 2. Natural atomic charges of the $\mathbf{N}$-atoms in ligands $\mathbf{3}$ and 33-25.

\begin{tabular}{ccccc}
$\begin{array}{c}\text { Donor } \\
\text { Atoms }^{\mathrm{a}}\end{array}$ & $\mathbf{H ( 3 )}$ & $\mathbf{C l ( 3 3 )}$ & $\mathrm{MeO}(34)$ & $\mathrm{Ph}(35)$ \\
\hline $\mathbf{N} 1, \mathbf{N} 10$ & -0.397 & -0.395 & -0.418 & -0.398 \\
$\mathbf{N}$ 12, N 26 & -0.488 & -0.489 & -0.492 & -0.487 \\
$\mathbf{N} 20, \mathbf{N} 34$ & -0.212 & -0.207 & -0.210 & -0.214 \\
$\mathbf{N} 19, \mathbf{N} 33$ & -0.211 & -0.210 & -0.212 & -0.212 \\
$\mathbf{\Sigma}$ & -2.616 & -2.602 & -2.664 & -2.622 \\
\hline
\end{tabular}

${ }^{\mathrm{a}}$ Numbering scheme in Figure 2.

The NBO data also highlights the fundamental role the 1,2,4triazine moieties play in creating the soft and thus highly selective molecular cavity of the ligands. ${ }^{19}$ The presence of neighboring $(\alpha)$ triazine $N$-atoms can be seen to reduce the point charge of both binding $N$-atoms significantly $(-0.212$ vs -0.488 for 3$)$. This observation is reaffirmed by Rao et al. who reported the 1,3-diazine containing analogue of BTPhen (BQPhen) to have significantly diminished selectivity for the trivalent actinides $\left(\mathrm{SF}_{\mathrm{Am} / \mathrm{Eu}}=10\right.$ vs. 110 for 3$) .^{43}$

\section{DISCUSSION}

It is now well established that $\mathrm{CyMe}_{4}-\mathrm{BTPhen}(3)$ and its analogues, extract trivalent metal ions from nitrate solutions according to equation 2:

$$
\mathrm{M}^{3+}{ }_{\text {(aq) }}+3 \mathrm{NO}_{3}^{-}{ }_{\text {(aq) }}+2 \mathrm{~L}_{\text {(org) }} \leftrightharpoons\left[\mathrm{ML}_{2}\left(\mathrm{NO}_{3}\right)\right]\left(\mathrm{NO}_{3}\right)_{2 \text { (org) }}
$$

However, if this were the only equilibrium process taking place, all systems including ligand $\mathbf{3}$ would exhibit distribution ratios strongly increasing with the $\mathrm{NO}_{3}{ }^{-}$and thus $\mathrm{HNO}_{3}$ concentration. Clearly this is not the case as analysis of Figures $5 \mathrm{a}-5 \mathrm{c}$ implies that a second, competing process must also be taking place. It was also clear that this second equilibrium is substantially affected by variation of the 4,7-substituents, suggesting that the competing process is most likely a result of the varying pKa values of $\mathbf{3}$ and 33-35 and thus their relative protonation states (equation 3 ). ${ }^{35}$

$$
\mathrm{L}+\mathrm{H}^{+} \leftrightharpoons \mathrm{LH}^{+}
$$

Analysis of the extraction data presented in Figures $5 a-5 c$, along with both the pKa measurements and stoichiometric preferences of ligands 3 and 33-35 (equations 2 and 3) allows the extraction behavior to be qualitatively rationalised. During extractions utilising parent 3 , the effects of increased $\mathrm{NO}_{3}{ }^{-}$ concentration are predominantly cancelled out by the decrease in free ligand concentration due to increased protonation ( $\mathrm{pKa}$
$=2.5$ ). This behavior is also true for compound 35, whose predicted pKa is expected to vary only slightly from that of $\mathbf{3}$. For ligand 34, the observed decrease in distribution ratios with increasing $\mathrm{HNO}_{3}$ concentration suggests that the effects of the increased basicity of the ligand ( $\mathrm{pKa}=3.9$ ) supersedes the effects of the increased $\mathrm{NO}_{3}{ }^{-}$concentration, leading to an inverse dependence. Conversely, for ligand $\mathbf{3 3}$ the observed increase in distribution ratios with increased $\mathrm{HNO}_{3}$ concentration is most likely due to the decreased ligand basicity $(\mathrm{pKa}=$ 1.7), thus decreased protonation combined with increased $\mathrm{NO}_{3}$ concentration. This behavior supports the supposition that it is the un-protonated species that ultimately undergoes metal complexation, and is therefore the extractant form that undertakes the transfer of the metal ions into the organic phase.

\section{CONCLUSIONS}

In summary, we have developed a modified synthetic route for the large scale preparation of BTPhen based ligand systems which avoids the use of hazardous $\mathrm{SeO}_{2}$. Significantly, we have also demonstrated that $\mathrm{CyMe}_{4}$-BTPhen (3) and three novel analogues, exhibit predictable extraction behavior in equilibrated systems. This predictability substantially enhances their suitability for future industrial scale partitioning processes such as the SANEX. Order of magnitude differences in the distribution ratios of the four ligands were observed, yet all were found to have comparable selectivity for $\mathrm{Am}$ (III) over $\mathrm{Eu}$ (III) $\left(\mathrm{SF}_{\mathrm{Am} / \mathrm{Eu}} \approx\right.$ 110) at equilibrium. This behavior is in contrast to that of a series of substituted BTP's (1) for which both distribution ratios and selectivity for $\mathrm{Am}$ (III) over $\mathrm{Eu}$ (III) increased as a function of ligand basicity. ${ }^{34}$ Furthermore, a less pronounced influence of substitution on extraction properties was found for BTPhens substituted at the 5- or 5,6-positions. ${ }^{20}$ For the first time, we have shown that complexation kinetics are substantially affected by backbone functionalisation. This paves the way for the design of future ligand systems that provide enhanced extraction kinetics. Evaluating the basicity, preferred stoichiometry and $\mathrm{HNO}_{3}$ dependence behavior of the ligands has provided a preliminary insight into the potential extraction mechanisms taking place, allowing the previously unexplained $\mathrm{HNO}_{3}$ independence of parent ligand 3 to be qualitatively rationalised. 4,7-phenyl-CyMe ${ }_{4}$-BTPhen (35) is a CHON compliant ligand which demonstrates extremely promising properties, including enhanced metal ion extraction kinetics, and provides a promising alternative to lead compound $\mathbf{3}$.

\section{ASSOCIATED CONTENT}

Supporting Information available: Full experimental details, key NMR spectra, solvent extraction procedures, TRLFS setup and procedures and X-ray crystallographic data are provided. This material is available free of charge via the Internet at http://pubs.acs.org."

\section{AUTHOR INFORMATION}

\section{Corresponding Author}

*Email: I.m.harwood@reading.ac.uk

*Email: roger.whitehead@manchester.ac.uk

\section{Notes}


${ }^{\ddagger}$ Pre-equilibrium values.

*The authors declare no competing financial interest.

\section{ACKNOWLEDGMENT}

We thank the EPSRC for funding a Nuclear Fission Research, Science and Technology DTC (Nuclear FiRST) studentship EP/G037140/1 (A.C.E) and core capability grant EP/K039547/1. This work was also supported by the SACESS project funded by the European Atomic Energy Community Seventh Framework under grant agreement No. 323282.

\section{REFERENCES}

1 K. L. Nash and M. Nilsson, Reprocessing and Recycling of Spent Nuclear Fuel, Elsevier, 2015.

2 C. Poinssot, B. Boullis and S. Bourg, Reprocessing and Recycling of Spent Nuclear Fuel, Elsevier, 2015.

3 The Royal Society Science Policy Centre Report, ISBN 9780854038916, 2011.

4 S. J. Zinkle, K. A. Terrani, J. C. Gehin, L. J. Ott and L. L. Snead, J. Nucl. Mater., 2014, 448, 374-379.

5 S. Monti, in International Atomic Energy Agency, 2015.

6 K. L. Nash and G. R. Choppin, Sep. Sci. Technol., 1997, 32, 255274.

7 D. D. Sood and S. K. Patil, J. Radioanal. Nucl. Chem. Artic., 1996, 203, 547-573.

8 P. J. Panak and A. Geist, Chem. Rev., 2013, 113, 1199-236.

9 C. A. Sharrad and D. M. Whittaker, Reprocessing and Recycling of Spent Nuclear Fuel, Elsevier, 2015.

G. Modolo, A. Geist and M. Miguirditchian, in Reprocessing and Recycling of Spent Nuclear Fuel, Elsevier, 2015, pp. 245-287. Recycling of Spent Nuclear Fuel, Elsevier, 2015. Netherlands, Dordrecht, 2006.

G. R. Choppin, J. Alloys Compd., 1995, 223, 174-179.

C. Adam, P. Kaden, B. B. Beele, U. Müllich, S. Trumm, A. Geist, P. J. Panak and M. A. Denecke, Dalton Trans., 2013, 42, 1406874.

N. Kaltsoyannis, Inorg.Chem., 2012, 52, 3407.

Z. Kolarik, U. Müllich and F. Gassner, Solvent Extr. Ion Exch.,

Z. Kolarik, U. Müllich and F. Gassner, Solvent Extr. Ion Exch., 1999, 17, 1155-1170.

M. J. Hudson, C. E. Boucher, D. Braekers, J. F. Desreux, M. G. B. Drew, M. R. Foreman, L. M. Harwood, C. Hill, C. Madic, F. Marken and T. G. A. Youngs, New J. Chem., 2006, 30, 1171.

M. J. Hudson, L. M. Harwood, D. M. Laventine and F. W. Lewis, Inorg. Chem., 2013, 52, 3414-28.

F. W. Lewis, L. M. Harwood, M. J. Hudson, M. G. B. Drew, J. F. Desreux, N. Bouslimani, G. Modolo, A. Wilden, M. Sypula, T. Vu and J. Simonin, J. Am. Chem. Soc., 2011, 133, 13093-13102.

A. Afsar, D. M. Laventine, L. M. Harwood, M. J. Hudson and A. Geist, Chem. Commun., 2013, 49, 8534-6.

A. F. Larsen and T. Ulven, Org. Lett., 2011, 13, 21-23.

L. M. Harwood, F. W. Lewis, M. J. Hudson, J. John and P. Distler, Solvent Extr. Ion Exch., 2011, 29, 551-576.

A. Afsar, L. M. Harwood, M. J. Hudson, J. Westwood and A. Geist, Chem. Commun., 2015, 51, 5860-5863.

N. T. Coogan, M. A. Chimes, J. Raftery, P. Mocilac and M. A. Denecke, J. Org. Chem., 2015, 80, 8684-8693.

F. H. Case, J. Org. Chem., 1965, 30, 931-3.

A. Geist, C. Hill, G. Modolo, M. R. Foreman, M. Weigl, K. Gompper and M. J. Hudson, Solvent Extr. Ion Exch., 2006, 24, 463-483.

http://www.technocomm.co.uk.

D. M. Whittaker, T. L. Griffiths, M. Helliwell, A. N. Swinburne, L.
J. Bezençon, M. B. Wittwer, B. Cutting, M. Smieško, B. Wagner, M. Kansy and B. Ernst, J. Pharm. Biomed. Anal., 2014, 93, 147155.

E. Breitmaier and K. H. Spohn, Tetrahedron, 1973, 29, 11451152.

J. Henderson, Am. J. Physiol., 1907, 21, 250-255.

K. A. Hasselbalch, Biochem. Z., 1917, 78, 112.

L. Grycová, R. Dommisse, L. Pieters and R. Marek, Magn. Reson. Chem., 2009, 47, 977-981.

S. Trumm, G. Wipff, A. Geist, P. J. Panak and T. Fanghänel, Radiochim. Acta, 2011, 99, 13-16.

A. Bremer, D. M. Whittaker, C. Sharrad, A. Geist and P. J. Panak, Dalton Trans., 2013, 43, 2684-2694.

S. Trumm, G. Lieser, M. R. Foreman, P. J. Panak, A. Geist and T. Fanghänel, Dalton Trans., 2010, 39, 923-929.

C. Wagner, U. Müllich, A. Geist and P. J. Panak, Solvent Extr. Ion Exch., 2015, 6299, 1-11.

F. W. Lewis, L. M. Harwood, M. J. Hudson, M. G. B. Drew, V. Hubscher-Bruder, V. Videva, F. Arnaud-Neu, K. Stamberg and S. Vyas, Inorg. Chem., 2013, 52, 4993-5005.

T. Wróblewski, L. Ziemczonek, A. M. Alhasan and G. P. Karwasz, Eur. Phys. J. Spec. Top., 2007, 144, 191-195.

G. Benay, R. Schurhammer and G. Wipff, Phys. Chem. Chem. Phys., 2011, 13, 2922-34.

2 A. Bhattacharyya, T. Gadly, P. K. Mohapatra, S. K. Ghosh, D. Manna, T. K. Ghanty and V. K. Manchanda, RSC Adv., 2012, 2, 7066.

Y. Yang, J. Liu, L. Yang, K. Li, H. Zhang, S. Luo and L. Rao, Dalt. Trans., 2015, 8959-8970.

William M. Nelson, Green Solvents for Chemistry: Perspectives and Practice, Oxford University Press, USA, 2003.

G. Benay and G. Wipff, J. Phys. Chem. B, 2013, 117, 1110-22. R. G. Pearson, Proc. Natl. Acad. Sci. U. S. A., 1986, 83, 84408441.

W. Yang and R. G. Parr, Proc. Natl. Acad. Sci. U. S. A., 1985, 82, 6723-6726. 1999, 17, 23-32. S. Natrajan, F. W. Lewis, L. M. Harwood, S. A. Parry and C. A. Sharrad, Inorg. Chem., 2013, 52, 3429-44.
P. W. Ayers and R. G. Parr, J. Am. Chem. Soc., 2000, 122, 20102018.

7759. 
